Interaction, Pair Formation and Force of Infection Terms in Sexually Transmitted Diseases

\author{
Stavros Busenberg \\ Department of Mathematics, Harvey Mudd College, Claremont CA 91711 USA
}

$$
\text { and }
$$

Carlos Castillo-Chavez

Biometrics Unit/Center for Applied Math, 341 Warren Hall, Cornell University

Ithaca NY 14853, USA

BU-1030-M

Revised September 1989 
Interaction, Pair Formation and Force of Infection Terms in Sexually

Transmitted Diseases

\author{
Stavros Busenberg \\ Department of Mathematics \\ Harvey Mudd College \\ Claremont, California 91711 \\ U. S.
}

\author{
Carlos Castillo-Chavez ${ }^{1}$ \\ Biometrics Unit/ Center for Applied Math. \\ 341 Warren Hall \\ Cornell University \\ Ithaca, NY 14853-7801 \\ U.S.
}

\begin{abstract}
A central question in the study of the dynamics of sexually-transmitted diseases - one emphasized by the AIDS epidemic - is that of mixing. In this note we formulate a generalization of the Blythe and Castillo-Chavez social/sexual framework for human interactions through the incorporation of age-structure, and derive an explicit expression for the general solution to this formulation. An age-structured epidemic model for a single sexually-active homosexual population, stratified by risk and age, with arbitrary risk and agedependent mixing and variable infectivity is formulated. In the special case of proportionate mixing in age and risk, an explicit expression for the basic reproductive number is given.
\end{abstract}

Introduction

Theoretical models have shown that the key factors, given the present information, determining the dynamics of HIV (human immunodeficiency virus, the etiological agent for AIDS) are variable infectivity and mixing. In this article, we formulate a general framework for age- and risk- (average number of sexual partners per unit time) dependent mixing. This framework generalizes those currently found in the literature and hence all specific forms of mixing presently used fit within our framework (for a more detailed discussion see the final section). In addition, we state (without proof) a representation theorem that includes all

1 To whom correspondence should be addressed 
possible solutions to this framework. If preference (like-with-like, etc.) is a central (and measurable) determinant of social/sexual dynamics, then our representation theorem solves the mixing problem for a homosexual population.

The mathematical literature on age-dependent models (see Castillo-Chavez $[1,2,3]$ and references therein) shows that mixing determines one of the nonlinear terms. Further, in the absence of nonlinear per capita birth and death rates, mixing is the only source of nonlinear phenomena. Biologically realistic mixing terms are provided by the "mass-action" law and proportionate mixing. Models for the AIDS epidemic have shown that other types of mixing have to be explored (see Jacquez et al [4], Hyman and Stanley [5]). Our representation theorem provides all possible nonlinear expressions for the "force" of infection (new cases per unit time) and hence, opens the possibility of evaluating past and current model assumptions.

The local dynamics of many epidemiological models are generally governed by the basic reproductive number $\left(R_{0}\right)$, which is usually defined as the number of secondary infections generated by a typical infectious individual in a population of susceptibles (see Diekmann et al [6]). Usually the maintenance of the disease at endemic levels can occur only if $R_{0}>1$, and this fact allows one to consider strategies that can reduce $R_{0}$ below its critical value. Approaches of this type have long been valuable in disease management, for example in the development of vaccination strategies for other diseases, or in educational programs for reducing transmission. In this article, we note that the reproductive number is given implicitly by a nonlinear function of the mixing and the infectivity. Hence, it is not possible to find an explicit expression for the reproductive number, except in very special situations such as proportionate mixing. However, a formula for the reproductive number in the case of proportionate mixing may be very useful in order to study the relative effects of distinct control measures.

In this paper for the first time, a formula for the reproductive number that involves risk, age, and variable infectivity is presented. For our model, $R_{0}>1$ implies the existence of an endemic state (i.e. the disease will be maintained). Since our main objective is to make these results available to those researchers interested in modelling the AIDS epidemic we concentrate on presenting some of our key results. Further results, more detailed examples, and the mathematical details will be published elsewhere (see [7]).

\section{Mixing framework}

We consider a single group of sexually-active homosexual individuals who are structured according to the following variables: $\mathrm{a}=$ age ; $\tau=$ time since infection ; $\mathrm{r}=$ activity or risk level. In addition, we let $\mathrm{N}(\mathrm{r}, \mathrm{a}, \tau, \mathrm{t})$ denote the total population density per unit age, activity, 
and time since infection, at time $t$. This population is divided into the following epidemiological classes: $\mathrm{S}=$ susceptible, $\quad \mathrm{I}$ = asymptomatic infective, $\mathrm{A}=$ symptomatic infective. Note that the $I$ class can include the traditional exposed but not infective class $E$, by taking simply the infectivity of an $I$ individual to be zero when $\tau$ is less than a given threshold $\tau_{0}$, or by employing some probability measure on the $\tau$ variable. We assume that $\tau$ is a hidden internal variable that does not distinguish individuals other than through their level of infectivity, and perhaps their mortality. For the case of AIDS, we let $\mathrm{T}=\mathrm{S}+\int_{0}^{\infty} \mathrm{I}(\mathrm{r}, \mathrm{a}, \tau, \mathrm{t}) \mathrm{d} \tau=$ total age and activity-level density of the population active in disease transmission contacts; i.e., we assume that A-individuals ("full-blown" AIDS) are sexually inactive. Sexual mixing is defined through the mixing function:

$$
\begin{aligned}
\rho\left(r, a, r^{\prime}, a^{\prime}, t\right) & =\text { proportion of partners of an }(r, a) \text { individual (i.e., a person } \\
& \text { of activity level } r \text { at age a) who are }\left(r^{\prime}, a^{\prime}\right) \text { individuals at } \\
& \text { time } t,
\end{aligned}
$$

and we let

$$
\begin{aligned}
\mathrm{C}(\mathrm{r}, \mathrm{a}, \mathrm{T}(\mathrm{r}, \mathrm{a}, \mathrm{t}))= & \text { expected or average number of partners per unit time; } \\
& \text { of an }(\mathrm{r}, \mathrm{a}) \text { individual, given that the sexually-active } \\
& \text { population density is } \mathrm{T}(\mathrm{r}, \mathrm{a}, \mathrm{t}) . \text { We assume that } \mathrm{C} \geq 0 .
\end{aligned}
$$

The following natural conditions characterize the mixing function :

(i) $\rho \geq 0$,

(ii) $\int_{0}^{\infty} \int_{0}^{\infty} \rho\left(\mathrm{r}, \mathrm{a}, \mathrm{r}^{\prime}, \mathrm{a}^{\prime}, \mathrm{t}\right) \mathrm{d} \mathrm{r}^{\prime} \mathrm{da}^{\prime}=1$,

(iii) $\rho\left(\mathrm{r}, \mathrm{a}, \mathrm{r}^{\prime}, \mathrm{a}^{\prime}, \mathrm{t}\right) \mathrm{C}(\mathrm{r}, \mathrm{a}, \mathrm{T}(\mathrm{r}, \mathrm{a}, \mathrm{t})) \mathrm{T}(\mathrm{r}, \mathrm{a}, \mathrm{t})=\rho\left(\mathrm{r}^{\prime}, \mathrm{a}^{\prime}, \mathrm{r}, \mathrm{a}\right) \mathrm{C}\left(\mathrm{r}^{\prime}, \mathrm{a}^{\prime}, \mathrm{T}\left(\mathrm{r}^{\prime}, \mathrm{a}^{\prime}, \mathrm{t}\right)\right) \mathrm{T}\left(\mathrm{r}^{\prime}, \mathrm{a}^{\prime}, \mathrm{t}\right)$,

(iv) $\mathrm{C}(\mathrm{r}, \mathrm{a}, \mathrm{T}(\mathrm{r}, \mathrm{a}, \mathrm{t})) \mathrm{T}(\mathrm{r}, \mathrm{a}, \mathrm{t}) \mathrm{C}\left(\mathrm{r}^{\prime}, \mathrm{a}^{\prime}, \mathrm{T}\left(\mathrm{r}^{\prime}, \mathrm{a}^{\prime}, \mathrm{t}\right)\right) \mathrm{T}\left(\mathrm{r}^{\prime}, \mathrm{a}^{\prime}, \mathrm{t}\right)=0 \Rightarrow \rho\left(\mathrm{r}, \mathrm{a}, \mathrm{r}^{\prime}, \mathrm{a}^{\prime}\right)=0$,

Condition (ii) is due to the fact that $\rho$ is a proportion. Condition (iii) simply states that the total number of pairs of $(r, a)$ individuals with $\left(r^{\prime}, a^{\prime}\right)$ individuals equals the total number of pairs of $\left(\mathbf{r}^{\prime}, \mathrm{a}^{\prime}\right)$ individuals with $(\mathrm{r}, \mathrm{a})$ individuals (all this is per unit time, age, and time since infection). Condition (iv) says that there is no mixing in the age and activity levels where there are no active individuals; i.e., on the set $S=\left\{\left(\mathrm{r}, \mathrm{a}, \mathrm{r}^{\prime}{ }^{\prime}, \mathrm{a}^{\prime}{ }^{\prime}\right)\right.$ : $\left.\mathrm{C}(\mathrm{r}, \mathrm{a}, \mathrm{T}(\mathrm{r}, \mathrm{a}, \mathrm{t})) \mathrm{T}(\mathrm{r}, \mathrm{a}, \mathrm{t}) \mathrm{C}\left(\mathrm{r}^{\prime}, \mathrm{a}^{\prime}, \mathrm{T}\left(\mathrm{r}^{\prime}, \mathrm{a}^{\prime}, \mathrm{t}\right)\right) \mathrm{T}\left(\mathrm{r}^{\prime}, \mathrm{a}^{\prime}, \mathrm{t}\right)=0\right\}$.

Since the above properties hold for all $t \geq 0$, we omit $t$; to further simplify the discussion we often assume that $\mathrm{C}=\mathrm{C}(\mathrm{r}, \mathrm{a})$. 
There are situations when it is necessary to consider mixing functions $\rho$ which are Dirac delta functions (see Nold [8], Jacquez et al. [4], Blythe and Castillo-Chavez [9], CastilloChavez and Blythe [10]), or, more generally, distributions or generalized functions. The above conditions (i)-(iv) also characterize these mixing distributions, provided that they are interpreted appropriately. Explicitly, two modifications to the interpretation of conditions (i) and (iv) are necessary:

(i') $\rho \geq 0$ in the sense of distributions, i.e.,

$$
\int_{0}^{\infty} \int_{0}^{\infty} \rho\left(\mathrm{r}, \mathrm{a}, \mathrm{r}^{\prime}, \mathrm{a}^{\prime}\right) \mathrm{f}\left(\mathrm{r}^{\prime}, \mathrm{a}^{\prime}\right) \mathrm{d} \mathrm{r}^{\prime} \mathrm{da} \mathrm{a}^{\prime} \geq 0 \text { for all } \mathrm{f} \geq 0, \text { and }
$$

(iv') $\rho\left(\mathrm{r}, \mathrm{a}, \mathrm{r}^{\prime}, \mathrm{a}^{\prime}\right)=0$ on a set $\mathrm{S}$, which means

$$
\int_{S} \int \rho\left(\mathrm{r}, \mathrm{a}, \mathrm{r}^{\prime}, \mathrm{a}^{\prime}\right) \mathrm{f}\left(\mathrm{r}, \mathrm{a}^{\prime}\right) \mathrm{drda} \mathrm{a}^{\prime}=0 \text { for all } \mathrm{f} .
$$

In writing the conditions characterizing $\rho$ we have exhibited their functional dependence on $\left(r, a, r^{\prime}, a^{\prime}\right)$ and, for notational convenience, suppressed their dependence on $t$ and $T$.

Pair formations can involve selectivity (according to age or activity level) by individuals, they can be random pairings without regard to these variables, or they can be any combination or mixture of the two extremes. A detailed discussion of these possibilities and of the restrictions they place on the mixing function $\rho$ can be found in [7].

The effects of mixing on disease transmission can be modelled through the incidence rate (new infected cases per unit time) or "force" of infection. We begin by letting $\beta\left(r, a, \tau, r^{\prime}, a^{\prime}\right)$ $=$ the probability that $a$ pairing between $a\left(r^{\prime}, a^{\prime}, \tau\right)$ infective individual and an $(r, a)$ susceptible will lead to the passing of the infection to the susceptible. The force of infection term $\mathrm{B}$ takes the form:

$$
\mathrm{B}(\mathrm{r}, \mathrm{a}, \mathrm{t})=\mathrm{S}(\mathrm{r}, \mathrm{a}, \mathrm{t}) \mathrm{C}(\mathrm{r}, \mathrm{a}, \mathrm{T}(\mathrm{r}, \mathrm{a}, \mathrm{t})) \int_{0}^{\infty} \int_{0}^{\infty} \int_{0}^{\infty} \beta\left(\mathrm{r}, \mathrm{a}, \tau, \mathrm{r}^{\prime}, \mathrm{a}^{\prime}\right) \rho\left(\mathrm{r}, \mathrm{a}, \mathbf{r}^{\prime}, \mathrm{a}^{\prime}\right) \frac{\mathrm{I}\left(\mathrm{r}^{\prime}, \mathrm{a}^{\prime}, \tau, \mathrm{t}\right)}{\mathrm{T}\left(\mathbf{r}^{\prime}, \mathrm{a}^{\prime}, \mathrm{t}\right)} \mathrm{d} \mathbf{r}^{\prime} \mathrm{da} \mathrm{a}^{\prime} \mathrm{d} \tau, .
$$


since a proportion $\mathrm{I} / \mathrm{T}$ of the contacts of a susceptible individuals is with infectives.

The implied dynamics for the susceptible class are governed by

$$
\frac{\partial \mathrm{S}}{\partial \mathrm{t}}(\mathrm{r}, \mathrm{a}, \mathrm{t})+\frac{\partial \mathrm{S}}{\partial \mathrm{a}}(\mathrm{r}, \mathrm{a}, \mathrm{t})+\mu(\mathrm{r}, \mathrm{a}, \mathrm{t}) \mathrm{S}(\mathrm{r}, \mathrm{a}, \mathrm{t})=\Lambda(\mathrm{r}, \mathrm{a}, \mathrm{t}, \mathrm{T}(\mathrm{a}, \mathrm{r}, \mathrm{t}))-\mathrm{B}(\mathrm{r}, \mathrm{a}, \mathrm{t})
$$

where $\Lambda$ denotes the "recruitment" rate into the susceptible class, and $\mu$ denotes the natural per capita mortality rate. We observe that there are several constitutive forms of the interaction term $\rho$; examples without age structure can be found in Blythe and CastilloChavez [9], Castillo-Chavez and Blythe [10]. A table that considers several possibilities, for age and activity dependent mixing, can be found in Busenberg and Castillo-Chavez [9], where the nine general cases discussed in detail include proportionate mixing in the age variable only, proportionate mixing in the activity variable only, and proportionate mixing in both age and partner variables. One of the simplest forms of mixing is that of proportionate or random mixing, and in our present framework, this includes both variables (age and activity level) and is given by a generalization of that used for situations without age-structure by Anderson and May [11] and May and Anderson [12]:

$$
\bar{\rho}\left(\mathrm{r}, \mathrm{a}, \mathrm{r}^{\prime}, \mathrm{a}^{\prime}\right)=\frac{\mathrm{C}\left(\mathrm{r}^{\prime}, \mathrm{a}^{\prime}, \mathrm{T}\left(\mathrm{r}^{\prime}, \mathrm{a}^{\prime}, \mathrm{t}\right)\right) \mathrm{T}\left(\mathrm{r}^{\prime}, \mathrm{a}^{\prime}, \mathrm{t}\right)}{\int_{0}^{\infty} \int_{0}^{\infty} \mathrm{C}\left(\mathrm{r}^{\prime}, \mathrm{a}^{\prime}, \mathrm{T}\left(\mathrm{r}^{\prime}, \mathrm{a}^{\prime}, \mathrm{t}\right)\right) \mathrm{T}\left(\mathrm{r}^{\prime}, \mathrm{a}^{\prime}, \mathrm{t}\right) \mathrm{d \textrm {a } ^ { \prime } \mathrm { dr }}}
$$

This solution plays an important role in the determination of all possible solutions to the mixing framework (i)-(ii)-(iii)-(iv). Busenberg and Castillo-Chavez, [7] have established the following results:

(I) The only separable mixing function, i.e. $\rho\left(\mathrm{r}, \mathrm{a}, \mathrm{r}^{\prime}, \mathrm{a}^{\prime}\right)=\rho_{1}(\mathrm{r}, \mathrm{a}) \rho_{2}\left(\mathrm{r}^{\prime}, \mathrm{a}^{\prime}\right)$, satisfying conditions (i)-(ii)-(iii)-(iv) is the total proportionate mixing $\bar{\rho}$ given by (3).

(II) If we let

$$
h(r, a, t)=C(r, a, T(r, a, t)) T(r, a, t),
$$

then the general solution of (i)-(ii)-(iii) has the form (omitting time) 


$$
\rho\left(\mathbf{r}, \mathrm{a}, \mathbf{r}^{\prime}, \mathrm{a}^{\prime}\right)=\tilde{\rho}\left(\mathbf{r}^{\prime}, \mathrm{a}^{\prime}\right)+\psi\left(\mathrm{r}, \mathrm{a}, \mathbf{r}^{\prime}, \mathrm{a}^{\prime}\right)
$$

where $\psi$ satisfies:

$$
\begin{gathered}
\psi \geq 0, \int_{0}^{\infty} \int_{0}^{\infty} \psi\left(\mathrm{r}, \mathrm{a}, \mathrm{r}^{\prime}, \mathrm{a}^{\prime}\right) \mathrm{d} \mathrm{r}^{\prime} \mathrm{da} \mathrm{a}^{\prime}=0, \int_{0}^{\infty} \int_{0}^{\infty} \psi\left(\mathrm{r}, \mathrm{a}, \mathrm{r}^{\prime}, \mathrm{a}^{\prime}\right) \mathrm{h}\left(\mathrm{r}^{\prime}, \mathrm{a}^{\prime}\right) \mathrm{d} \mathrm{r}^{\prime} \mathrm{da}=0, \text { and } \\
\psi\left(\mathrm{r}, \mathrm{a}, \mathrm{r}^{\prime}, \mathrm{a}^{\prime}\right) \mathrm{h}(\mathrm{r}, \mathrm{a})=\psi\left(\mathrm{r}^{\prime}, \mathrm{a}^{\prime}, \mathrm{r}, \mathrm{a}\right) \mathrm{h}\left(\mathrm{r}^{\prime}, \mathrm{a}^{\prime}\right)
\end{gathered}
$$

(III) If we let $\phi\left(r, a, r^{\prime}, a^{\prime}\right)$, be jointly symmetric in the $(r, a)$ and $\left(r^{\prime}, a^{\prime}\right)$ variables- - i.e., $\phi\left(\mathrm{r}, \mathrm{a}, \mathrm{r}^{\prime}, \mathrm{a}^{\prime}\right)=\phi\left(\mathrm{r}^{\prime}, \mathrm{a}^{\prime}, \mathrm{r}, \mathrm{a}\right)$, and assume that $\int_{0}^{\infty} \int_{0}^{\infty} \bar{\rho}\left(\mathrm{r}^{\prime}, \mathrm{a}^{\prime}\right) \phi\left(\mathrm{r}, \mathrm{a}, \mathrm{r}^{\prime}, \mathrm{a}^{\prime}\right) \mathrm{d} \mathrm{r}^{\prime} \mathrm{da} \mathrm{a}^{\prime}=1 \ldots$ then

we have the following general representation formula for the mixing function satisfying (i)(ii)-(iii)-(iv):

$$
\rho\left(\mathrm{r}, \mathrm{a}, \mathbf{r}^{\prime}, \mathrm{a}^{\prime}\right)=\bar{\rho}\left(\mathrm{r}^{\prime}, \mathrm{a}^{\prime}\right) \phi\left(\mathrm{r}^{\prime}, \mathrm{a}^{\prime}, \mathrm{r}, \mathrm{a}\right) .
$$

Conversely, every mixing function $\rho$ that satisfies (i)-(ii)-(iii)-(iv) is given by the form (8), where $\phi$ is symmetric and satisfies the hypothesis of the theorem.

Using the above results and condition (iv) we derive a fundamental explicit representation formula for the construction of arbitrary mixing functions. This representation is based on perturbations of a particularly convenient special form.

Representation Theorem. To describe the representation formula given by this theorem, we let $\phi: \Re_{+}^{4} \rightarrow \Re^{+}$be a measurable and jointly symmetric function, and suppose that

$$
\begin{aligned}
& \int_{0}^{\infty} \int_{0}^{\infty} \bar{\rho}\left(\mathbf{r}^{\prime}, \mathrm{a}^{\prime}\right) \phi\left(\mathrm{r}, \mathrm{a}, \mathrm{r}^{\prime}, \mathrm{a}^{\prime}\right) \mathrm{dr} \mathrm{r}^{\prime} \mathrm{da} \mathrm{a}^{\prime} \leq 1 \text { and } \\
& \int_{0}^{\infty} \int_{0}^{\infty} \bar{\rho}(\mathrm{r}, \mathrm{a})\left\{\int_{0}^{\infty} \int_{0}^{\infty} \bar{\rho}\left(\mathrm{r}^{\prime}, \mathrm{a}^{\prime}\right) \phi\left(\mathrm{r}, \mathrm{a}, \mathrm{r}^{\prime}, \mathrm{a}^{\prime}\right) \mathrm{d} \mathrm{r}^{\prime} \mathrm{da} \mathrm{a}^{\prime}\right\} \mathrm{drda}<1 .
\end{aligned}
$$

Defining $\rho_{1}(\mathrm{r}, \mathrm{a})$ by

$$
\rho_{1}(\mathrm{r}, \mathrm{a})=1-\int_{0}^{\infty} \int_{0}^{\infty} \bar{\rho}\left(\mathrm{r}^{\prime}, \mathrm{a}^{\prime}\right) \phi\left(\mathrm{r}^{\prime}, \mathrm{a}^{\prime}, \mathrm{r}, \mathrm{a}\right) \mathrm{dr} \mathrm{r}^{\prime} \mathrm{da}
$$

we arrive at the following fundamental representation formula for a mixing function

$$
\rho\left(\mathrm{r}, \mathrm{a}, \mathrm{r}^{\prime}, \mathrm{a}^{\prime}\right)=\bar{\rho}\left(\mathrm{r}^{\prime}, \mathrm{a}^{\prime}\right) \llbracket \frac{\rho_{1}(\mathrm{r}, \mathrm{a}) \rho_{1}\left(\mathrm{r}^{\prime}, \mathrm{a}^{\prime}\right)}{\iint_{0}^{\infty} \int_{0}^{\infty} \bar{\rho}\left(\mathrm{r}^{\prime}, \mathrm{a}^{\prime}\right) \rho_{1}\left(\mathrm{r}^{\prime}, \mathrm{a}^{\prime}\right) \mathrm{dr} \mathrm{r}^{\prime} \mathrm{da}}+\phi\left(\mathrm{r}, \mathrm{a}, \mathrm{r}^{\prime}, \mathrm{a}^{\prime}\right) \rrbracket .
$$


The converse also holds; that is, for every mixing function $\rho$ there exists $\phi$ satisfying the hypotheses of the theorem such that $\rho$ is given by (10) with $\rho_{1}$ defined by (9). A similar result holds when we allow $\rho$ to be a generalized function and include the possibility of delta functions or other distributions

An elementary but important result is that a convex combination of mixing functions is also a mixing function. Specifically, if $\alpha_{1}, \ldots \alpha_{N}$ are positive constants such that $\sum_{i=1}^{N} \alpha_{i}=1$, and $\rho_{1}, \ldots, \rho_{N}$ are mixing functions, then $\sum_{i=1}^{N} \alpha_{i} \rho_{i}$ is a mixing function.

Here we include only the proof of (I). The proof of (II)-(III) and the representation theorem, as well as the proofs of further results for specific cases can be found in Busenberg and Castillo-Chavez [7].

Proportionate mixing (in age and risk) $\bar{\rho}$ is the only separable solution that satisfies the mixing axioms (i)-(iv).

Proof:

A mixing function $\rho$ is called separable if it can be written in the form

$$
\rho\left(\mathrm{r}, \mathrm{a}, \mathrm{r}^{\prime}, \mathrm{a}^{\prime}\right)=\rho_{1}(\mathrm{r}, \mathrm{a}) \rho_{2}\left(\mathrm{r}^{\prime}, \mathrm{a}^{\prime}\right)
$$

Note that the total proportionate mixing function $\bar{\rho}$ is separable.

Suppose that $\rho$ is separable; then a direct substitution of this separable solution in (ii) leads to

$$
\left.\rho_{1}(\mathrm{r}, \mathrm{a})=\frac{1}{\iint_{0}^{\infty} \rho_{2}\left(\mathrm{r}^{\prime}, \mathrm{a}^{\prime}\right) \mathrm{d} \mathrm{r}^{\prime} \mathrm{da} \mathrm{a}^{\prime}}=\mathrm{k} \text { (a constant }\right)
$$

Hence it follows that $\rho\left(\mathrm{r}, \mathrm{a}, \mathrm{r}^{\prime}, \mathrm{a}^{\prime}\right)=\mathrm{k} \rho_{2}\left(\mathrm{r}^{\prime}, \mathrm{a}^{\prime}\right)$.

We next note a useful relation obtained by integrating (iii) over the variables $r^{\prime}$ and $a^{\prime}$ and using condition (ii),

$$
\mathrm{C}(\mathrm{r}, \mathrm{a}, \mathrm{T}(\mathrm{r}, \mathrm{a})) \mathrm{T}(\mathrm{r}, \mathrm{a})=\int_{0}^{\infty} \int_{0} \rho\left(\mathrm{r}^{\prime}, \mathrm{a}^{\prime}, \mathrm{r}, \mathrm{a}\right) \mathrm{C}\left(\mathrm{r}^{\prime}, \mathrm{a}^{\prime}, \mathrm{T}\left(\mathrm{r}^{\prime}, \mathrm{a}^{\prime}\right)\right) \mathrm{T}\left(\mathrm{r}^{\prime}, \mathrm{a}^{\prime}\right) \mathrm{dr} \mathrm{r}^{\prime} \mathrm{da} \mathrm{a}^{\prime}
$$


which we can also write using (4) as

$$
\mathrm{f}(\mathrm{r}, \mathrm{a})=\int_{0}^{\infty} \int_{0} \rho\left(\mathrm{r}^{\prime}, \mathrm{a}^{\prime}, \mathrm{r}, \mathrm{a}\right) \mathrm{f}\left(\mathrm{r}^{\prime}, \mathrm{a}^{\prime}\right) \mathrm{d} \mathbf{r}^{\prime} \mathrm{da} \mathbf{a}^{\prime} .
$$

Substituting the expression for $\rho$ in $(* *)$, we obtain

Hence,

$$
f(r, a)=k \rho_{2}(r, a) \int_{0}^{\infty} \int_{0}^{f}\left(r^{\prime}, a^{\prime}\right) d r^{\prime} d a^{\prime}
$$

$$
k \rho_{2}(r, a)=\frac{f(r, a)}{\iint_{0}^{\infty} f\left(\left(r^{\prime}, a^{\prime}\right) d r^{\prime} d a^{\prime}\right.}
$$

that is, $\rho=\bar{\rho}$. Since $\bar{\rho}$ satisfies (i)-(ii)-(iii)-(iv) the proof is complete.

Age and risk based model with variable infectivity

We now use some of the above observations to formulate a specific model. A dynamic model for the sexual spread of HIV/AIDS in a single sexually-active homosexual population is given by the following set of equations for $S(r, a, t), I(r, a, \tau, t)$, and $A(r, a, \tau, t)$ :

$$
\begin{aligned}
& \frac{\partial \mathrm{S}}{\partial \mathrm{t}}+\frac{\partial \mathrm{S}}{\partial \mathrm{a}}+\mu(\mathrm{a}) \mathrm{S}=\Lambda(\mathrm{r}, \mathrm{a}, \mathrm{t}, \mathrm{T}(\mathrm{a}, \mathrm{r}, \mathrm{t}))-\mathrm{B}(\mathrm{r}, \mathrm{a}, \mathrm{t}) \\
& \frac{\partial \mathrm{I}}{\partial \mathrm{t}}+\frac{\partial \mathrm{I}}{\partial \mathrm{a}}+\frac{\partial \mathrm{I}}{\partial \tau}+\{\mu(\mathrm{a})+\xi(\mathrm{a}, \tau)+\gamma(\mathrm{a}, \tau)\} \mathrm{I}=0 \\
& \frac{\partial \mathrm{A}}{\partial \mathrm{t}}+\frac{\partial \mathrm{A}}{\partial \mathrm{a}}+\frac{\partial \mathrm{A}}{\partial \tau}+\{\mu(\mathrm{a})+\eta(\mathrm{a}, \tau)\} \mathrm{A}=\gamma(\mathrm{a}, \tau) \mathrm{I}
\end{aligned}
$$

where

$$
\mathrm{S}(\mathrm{r}, \mathrm{o}, \mathrm{t})=\mathrm{I}(\mathrm{r}, 0, \tau, \mathrm{t})=\mathrm{A}(\mathrm{r}, 0, \tau, \mathrm{t})=0, \mathrm{I}(\mathrm{r}, \mathrm{a}, 0, \mathrm{t})=\mathrm{B}(\mathrm{r}, \mathrm{a}, \mathrm{t})
$$

and $\xi$ and $\eta$ denote the disease-induced mortalities. The other parameters are as previously defined.

For this model, we have obtained a general expression, which characterizes the 
reproductive number $R_{0}$ of the disease. This expression is obtained by formally substituting the expression for the endemic equilibrium, $\left(S^{*}(r, a), I^{*}(r, a, \tau)\right)$, calculated through the method of characteristics, into the force of infection, $B^{*}(r, a)=k^{*}\left(r, a, \rho^{*}\right) C(r, a) S^{*}(r, a)$, where $\rho^{*}$ denotes the mixing at equilibrium. This substitution lead us to a relationship of the form

$$
\mathrm{k}^{*}(\mathrm{r}, \mathrm{a})=\iint_{0}^{\infty} \mathbb{\|} \int_{0}^{\mathrm{a}^{\prime}} \beta\left(\mathrm{r}, \mathrm{a}, \tau, \mathrm{r}^{\prime}, \mathrm{a}^{\prime}\right) \mathrm{M}\left(\mathrm{k}^{*}, \mathrm{r}, \mathrm{a}, \mathrm{r}^{\prime}, \mathrm{a}^{\prime}\right) \mathrm{d} \tau \rrbracket \mathrm{d} \mathbf{r}^{\prime} \mathrm{d} \mathrm{a}^{\prime}
$$

where a $M \equiv M\left(k^{*}, r, a, r^{\prime}, a^{\prime}\right)$ denotes a nonlinear functional which depends on the particular mixing function $\rho^{*}$ but that always has the property that $M\left(0, r, a, r^{\prime}, a^{\prime}\right)=0$. We observe that $\mathrm{k}^{*}(\mathrm{r}, \mathrm{a}) \equiv 0$ is always a solution of $(15)$ and it corresponds to the infection-free state. Any other nonnegative solutions to (15) correspond to an endemic equilibrium. In the special case where $\rho=\bar{\rho}, \mathrm{C}$ and $\Lambda$ are independent of the active population density $\mathrm{T}$, and $\beta=\beta\left(\tau, \mathrm{r}^{\prime}, \mathrm{a}^{\prime}\right)$, we find the that the existence of an endemic state is dependent on the value of the basic reproductive number given by

$$
\begin{aligned}
& \mathrm{R}_{0}=\int_{0}^{\infty} \int_{0}^{\infty} \mathrm{C}\left(\mathrm{r}^{\prime}, \mathrm{a}^{\prime}\right)\left\{\int_{0}^{\mathrm{a}^{\prime}} \mathrm{e}^{-\mathrm{a}_{\mathrm{x}}^{\prime} \mu(\mathrm{y}) \mathrm{dy}} \Lambda\left(\mathrm{r}^{\prime}, \mathrm{x}\right) \mathrm{dx}\right\} \int_{0}^{\infty} \llbracket \beta\left(\tau, \mathrm{r}^{\prime}, \mathrm{a}^{\prime}\right) \mathrm{C}\left(\mathrm{r}^{\prime}, \mathrm{a}^{\prime}-\tau\right) \quad \mathrm{X} \\
& \mathrm{e}^{-\int_{0}^{\tau}\left[\mu\left(\mathrm{a}^{\prime}+\sigma-\tau\right)+\xi\left(\mathrm{a}^{\prime}+\sigma-\tau, \sigma\right)+\gamma\left(\mathrm{a}^{\prime}+\sigma-\tau, \sigma\right)\right] \mathrm{d} \sigma} \quad \mathrm{d} \tau \rrbracket \mathrm{d} \mathrm{a}^{\prime} \mathrm{d} \mathbf{r}^{\prime}
\end{aligned}
$$

which is easily computed from (15).

The basic reproductive number is a parameter of critical importance in the study of disease dynamics. It allows us to study the effects of demographic and epidemiological parameters in disease transmission. For example, we note that $R_{0}$ is given by three types of risk- and age- dependent expressions: those involving death-adjusted "recruitment", those involving time spent as infectiousy-appropriately weighted by infectivity, and those involving average sexual activity. Furthermore, we observe that any uniform increase in these 
expressions; i.e., an increase in the incubation period, in the mean number of sexual partners, or in the recruitment of susceptibles will generate an increase in the reproductive number. However, a change in any of these parameters, which represents an average increase over old age and activity classes, need not lead to an increase in $R_{0}$, and in fact, may cause $R_{0}$ to decrease due to the close coupling between these epidemiological parameters and the age- and activity level- dependent demographic parameters. The results concerning uniform increases agree in principle with those found for reproductive numbers for age-independent homogeneously mixing models, in which the reproductive number is given as the product of three factors: the mean infectious period, the mean number of sexual partners per unit time, and the average infectivity (see Anderson and May [11]). In addition, for models in which the mean number of sexual partners depends on the "recruitment" rate, we observe that the reproductive number is a nondecreasing function of this rate (see Castillo-Chavez et al. [13, 14, 15], and Thieme and Castillo-Chavez $[16,17])$. However, the lack of age- and activitylevel structure makes it impossible to use these simpler age- and activity-independent models in the fine tuning and testing of specific control measures. The expression for $R_{0}$, given by Equation (16), allows us to look at the effects of potential control measures that are targeted to individuals of specific age and activity levels.

\section{Conclusion}

In this note we have extended the mixing framework of Blythe and Castillo-Chavez through the incorporation of age-structure, and have found the general solution to the mixing problem for a homosexual population. This general solution, as well as a number of other results, are new even in the simpler contest with no age-dependence. We have further clarified the role of proportionate mixing by showing that it is the only separable solution. We have formulated a general epidemic model for a single, age-dependent, sexually active, homosexual population with distributed activity levels, and have obtained an explicit expression for the 
reproductive number for the special case of proportionate mixing.

Our work (Busenberg and Castillo-Chavez, [7]) shows that the reproductive number is a complex nonlinear function of the mixing. Future work should be devoted to the clarification of the role of the mixing function on the reproductive number. This may be partially accomplished by the systematic study of special cases, such as that of preferred mixing (see Nold [8], Jacquez et al. [4], Blythe and Castillo-Chavez [9], Castillo-Chavez and Blythe [10], and Busenberg and Castillo-Chavez [7], Castillo-Chavez et al. [15], Huang et al. [18, 19]).

We note (Andrea Pugliese's remark) that our mixing framework can be easily generalized to include geographical variability by assuming that each community has its own mixing function, $\rho^{j}\left(r, a, r^{\prime}, a^{\prime}\right)$, which denotes the proportion of partners of an $(r, a)$ individual who are $\left(r^{\prime}, a^{\prime}\right)$ individuals and that take place at location $j$. Each of these mixing functions satisfy the mixing axioms, and hence can be expressed through our representation theorem. To complete the model, the specification of a migration matrix such as that of Sattenspiel $[20,21]$ and Sattenspiel and Simon [22] is needed to model the movement of individuals between communities. Although the use of a general framework of this type could be very useful in theoretical consideration, its applicability to specific situations is probably quite limited due to the tremendous number of parameters involved.

Finally, we note that the extension of the above framework to two-sex populations is quite simple and specific solutions can be found. We are presently trying to determine the general solution to this two-sex framework. We note that the formulation of a two-sex framework along the lines of the one-sex framework described in this article provides with an alternative formulation to that of Dietz and Hadeler [23]. Models that consider pairs and follow the dynamics of pairs have been studied by Kendall [24], Fredrickson [25], Dietz and Hadeler [23], Dietz [26], Hadeler [27, 28], and Waldstätter [29]. Analogous models can be formulated using solutions to a two-sex framework similar to the one described in this article. Our approach (one - and two- sex frameworks) has perhaps the added advantage that allows us to compare the results of models with pairs and without pairs (i.e. the duration of each 
partnership is zero) from frameworks derived under the same basic assumptions. A manuscript discussing a model with pairs that incorporates this approach for specific mixing functions is under preparation (see Castillo-Chavez and Busenberg [30]).

\section{Acknowledgments}

This research has been partially supported by the Center for Applied Mathematics at Cornell University and NSF grant DMS-8703631 to S. B., and NSF grant DMS-8906580 and Hatch project grant NYC 151-409, USDA to C C-C. We thank them all for their generous support.

\section{References}

1. C. Castillo-Chavez, H. W. Hethcote, V. Andreasen, S. A. Levin, and W. M. Liu, Epidemiological models with age structure, proportionate mixing, and cross-immunity, $J$. Math. Biol. 27:233-258 (1989).

2. C. Castillo-Chavez, H. W. Hethcote, V. Andreasen, S. A. Levin, and W. M. Liu, Crossimmunity in the dynamics of homogeneous and heterogeneous populations, In: Mathematical ecology, L. Gross, T. G. Hallam, and S. A. Levin, eds., Proceedings, Autumn Course Research Seminars, Trieste 1986, pp. 303-316. Singapore: World Scientific Publ. Co. (1988).

3. C. Castillo-Chavez, Some applications of structured models in population dynamics, In: Applied mathematical ecology, Biomathematics 18, Springer-Verlag (in press).

4. J. A. Jacquez, C. P. Simon, J. Koopman, L. Sattenspiel and T. Perry, Modelling and analyzing HIV transmission: the effect of contact patterns, Math. Biosci. 92:119-199 (1988).

5. J. M. Hyman and E. A. Stanley, A risk based model for the spread of the AIDS virus, Math. Biosci. 90:415-473 (1988).

6. O. Diekmann, J. A. P. Heesterbeek, and J. A. J. Metz, On the definition of $R_{0}$ in models for infectious diseases in heterogeneous populations (ms.)

7. S. Busenberg and C. Castillo-Chavez, Risk and age-dependent mixing functions and force of infection terms in STD's (submitted).

8. A. Nold, Heterogeneity in disease-transmission modeling, Math. Biosci. 52:227-240 (1980). 
9. S. P. Blythe and C. Castillo-Chavez, Like-with-like preference and sexual mixing models, Math. Biosci. (in press).

10. C. Castillo-Chavez and S. P. Blythe, Mixing framework for social/sexual behavior, In: Mathematical and statistical approaches to AIDS epidemiology, C. Castillo-Chavez, ed., Lecture Notes in Biomathematics, Springer-Verlag (in press).

11. R. M. Anderson and R. M. May, Transmission dynamics of HIV infection, Nature, $326: 137-142$ (1987).

12. R. M. May and R. M. Anderson, The transmission dynamics of human immunodeficiency virus (HIV). Phil. Trans. R. Soc. London B, 321:565-607 (1989).

13. C. Castillo-Chavez, K. Cooke, W. Huang and S. A. Levin, On the role of long periods of infectiousness in the dynamics of acquired immunodeficiency syndrome (AIDS), In: Mathematical approaches to problems in resource management and epidemiology, $\mathrm{C}$. Castillo-Chavez, S. A. Levin and C. Shoemaker, eds., Lecture Notes in Biomathematics, Springer-Verlag (in press).

14. C. Castillo-Chavez, K. Cooke, W. Huang and S. A. Levin, On the role of long incubation periods in the dynamics of acquired immunodeficiency syndrome (AIDS), Part 1. Single population models, J. Math. Biol. (in press).

15. C. Castillo-Chavez, K. Cooke, W. Huang and S. A. Levin, Results on the dynamics for models for the sexual transmission of the human immunodeficiency virus, Applied Mathematics Letters, (in press).

16. H. R. Thieme and C. Castillo-Chavez, On the role of variable infectivity in the dynamics of the human immunodeficiency virus, In: Mathematical and statistical approaches to AIDS epidemiology, C. Castillo-Chavez, ed., Lecture Notes in Biomathematics, SpringerVerlag (in press).

17. H. R. Thieme and C. Castillo-Chavez, On the possible effects of infection-age-dependent infectivity in the dynamics of HIV/AIDS (manuscript in preparation).

18. W. Huang, C. Castillo-Chavez, K. Cooke and S. A. Levin, On the role of long incubation periods in the dynamics of acquired immunodeficiency syndrome (AIDS), Part 2. Multiple group models, In: Mathematical and statistical approaches to AIDS epidemiology, C. Castillo-Chavez, ed., Lecture Notes in Biomathematics, Springer-Verlag (in press).

19. W. Huang, K. Cooke and C. Castillo-Chavez, Stability and bifurcation for a multiple group model for the dynamics of HIV/AIDS transmission (mas.).

20. L. Sattenspiel, Population structure and the spread of disease, Human Biology, 59:411438 (1987).

21. L. Sattenspiel, Epidemics in nonrandomly mixing populations: a simulation. American Journal of Physical Anthropology, 73:251-265 (1987).

22. L. Sattenspiel and C. P. Simon, The spread and persistence of infectious diseases in structured populations. Math. Biosci. 90:341-366 (1988).

23. K. Dietz and K. P. Hadeler, Epidemiological models for sexually transmitted diseases. J. Math. Biol. 26:1-25 (1988). 
24. D. G. Kendall, Stochastic processes and population growth, Roy. Statist. Soc., Ser B, 2:230-264 (1949).

25. A. G. Fredrickson, A mathematical theory of age structure in sexual populations: Random mating and monogamous marriage models. Math. Biosci., 10:117-143 (1971).

26. K. Dietz, On the transmission dynamics of HIV, Math. Biosci. 90:397-414 (1988).

27. K. P. Hadeler, Pair formation in age-structured populations, Acta Applicandae Mathematicae, 14:91-102 (1989).

28. K. P. Hadeler, Modeling AIDS in structured populations (ms.).

29. R. Waldstätter, Pair formation in sexually transmitted diseases, In: Mathematical and statistical approaches to AIDS epidemiology, C. Castillo-Chavez, ed., Lecture Notes in Biomathematics, Springer-Verlag (in press).

30. C. Castillo-Chavez and S. Busenberg, Pair formation in age- and risk- structured populations (ms. under preparation). 